ISSN: 2162-3104 Print/ ISSN: 2166-3750 Online

Volume 8, Issue 4 (2018), pp. 1815-1830

(C) Journal of International Students

http://jistudents.org/

doi: 10.5281/zenodo.1467803

\title{
International Graduate Students: Agency, Intentionality, and Socialization Reciprocity
}

\author{
José Manuel Martínez \\ Michigan State University, USA \\ India C. Plough \\ Michigan State University, USA
}

\begin{abstract}
Using grounded theory methodology, this study explored the development and implementation of a Cultures and Languages across the Curriculum initiative in a residential college at Michigan State University. With a focus on international graduate students, our investigation led us to knowledgebuilding communities and to patterns of behavior that we have conceptualized as socialization reciprocity. We note two key characteristics of the knowledge-building communities created within the Cultures and Languages across the Curriculum program are agency and intentionality, and these can only be realized by starting from the premise that the contributions of all participants are essential to the community. We argue this is in contrast to the not uncommon assumption that the cultural, linguistic, and pedagogical knowledge of international graduate students is somehow deficient.
\end{abstract}

Keywords: cultures and languages across the curriculum, knowledgebuilding communities

Using grounded theory methodology, this study explored the development and initial implementation of a three-year pilot of a Cultures and Languages across the Curriculum (CLAC) initiative in the Residential College in the Arts and Humanities (RCAH) at Michigan State University (MSU). With a focus on the role of international graduate students, our investigation of the 
CLAC program led us to the concept of knowledge-building communities (KBCs). This provided us with a productive theoretical framework in which to situate the program for further examination. We discovered patterns of behavior that we have conceptualized as socialization reciprocity. To understand its emergence, we noted that two key characteristics of the KBCs created within the CLAC program are agency and intentionality. Furthermore, these can only be realized by starting from the premise that the contributions of all participants are essential to the community. We would argue that this is in stark contrast to the not uncommon assumption that the cultural, linguistic, and pedagogical knowledge of international graduate students is somehow deficient.

In order to contextualize our study, we provide a brief overview of the $\mathrm{RCAH}$, including two of its priorities: civic engagement and functional proficiency in a world language. We also describe Integrated Language Options (ILOs), one component of the CLAC program, in relatively greater detail as these are the places in which our international graduate students initially join the RCAH. We then turn to the study proper with a description of the research methods, a discussion of our findings, and conclusions.

During the writing of this article, the RCAH faculty completed a thorough review of the three-year pilot and have recommended not only the continuation of the CLAC program but also its expansion. We suggest that the success of this program, and indeed the advancement of knowledge and the vitality of the academy, depends on recognizing the assets that international graduate students bring to our institutions and abandoning the prevalent deficit view. By creating an environment that fosters KBCs, socialization reciprocity can emerge. In this way, "knowledge-building begets knowledge-building” (Scardamalia \& Bereiter, 1994, p. 275).

\section{CONTEXT: LIVE YOUR LEARNING}

The Residential College in the Arts and Humanities at Michigan State University is a young undergraduate college, accepting its first students the fall of 2007. The RCAH is an interdisciplinary college with a strong commitment to social justice, civic engagement, the visual and performing arts, and world languages and cultures. Academic (e.g., classrooms, faculty offices, theatre) and residential facilities (e.g., dormitory rooms, dining hall) are located in a single complex (two connected buildings) on the university campus. Freshmen are required to live in the RCAH residence halls; approximately $70 \%$ of sophomores and $30 \%$ of upper classmen elect to continue living in the RCAH. With a total enrollment of approximately 300 
students, the major is built on four cornerstones: world history, art and culture, ethics, and engaged learning. As part of the mission of a land-grant institution, a primary goal of the RCAH is to bring together students, faculty, staff, and community partners to improve individual well-being and the common good. As such, RCAH's curriculum includes required civic engagement $(\mathrm{CE})$ courses and also integrates $\mathrm{CE}$ throughout curricular and extra-curricular activities. A guiding definition for RCAH faculty states:

Learning to express yourself, carefully considering the wellbeing of others, critically questioning the way things are, and actively using the arts and humanities to design a more democratic, just and sustainable world--these are concerns of civic engagement. Civic engagement... is about protecting and exercising diversity. It is also about sharing responsibility with others. It is about immersing oneself in community and confronting unearned power and privilege. Perhaps most important of all, civic engagement is an adventure propelled by passion and creativity at a time when social equity, transcultural change and sustainability are critical concerns for all citizens. (DeLind \& Delgado, 2009, p. 4)

The RCAH degree also requires functional proficiency in a language other than English, affirming that in learning another language students are able to gain greater insight into other cultures as well as their own. The requirement can be fulfilled through coursework, a standardized test, an RCAH test of speaking proficiency, or a study abroad experience. World languages are not formally taught in the RCAH; rather, this instruction is housed in various departments across the University.

\section{Cultures and Languages Across the Curriculum}

The RCAH initiated the CLAC program to complement traditional language courses. The goal of the program is to provide opportunities for students to apply and strengthen their knowledge of world languages and cultures in a variety of curricular and extra-curricular contexts within the $\mathrm{RCAH}$ as well as in the wider community. The program was completing its third year of the pilot at the time of the study reported here. Each year, in collaboration with MSU's Graduate School, the RCAH offers competitive graduate student language fellowships in the CLAC program. Eligible graduate students are enrolled in any MSU college and have (near) native fluency in a language other than English. 


\section{CLAC Weekly Seminars}

Graduate students selected for the fellowship participate in weekly meetings with other RCAH fellowship recipients, faculty, and occasionally RCAH staff. There are overarching professional development goals in the scholarship of undergraduate teaching and learning for the graduate fellow weekly seminars. Language fellows are introduced to and gain experience in needs assessment, materials development, teaching methodology, and program evaluation. They are also encouraged to collaborate with RCAH faculty on the design and implementation of research projects in the aforementioned areas and to publish in peer-reviewed journals and present at professional conferences. International graduate fellows (the focus of the current article) represent many units on campus (e.g., Engineering, Education, Business) and countries from around the world (e.g., China, Colombia, Germany, Honduras, Iraq, Italy, Japan, Mexico, Senegal, Tunisia, United States, Vietnam).

Several seminars at the beginning of the semester are devoted to orientation to the RCAH and to the CLAC program, because the graduate fellows, as mentioned, are seeking degrees in various disciplines across campus and are unfamiliar with the RCAH and its student population. Graduate fellows and the director then co-construct the syllabus, and through the course of a semester, the content has extended from the area of second language teaching and learning to its relationship to general education theory and pedagogy.

Graduate fellows also facilitate Integrated Language Options (ILOs). Therefore, early in the semester, the seminars take on a workshop format that are led by individual fellows and frequently serve as a time for fellows to work through ILO issues of relevance to them, discussing challenges and sharing successful strategies.

\section{Integrated Language Options}

ILOs follow an interactionist perspective of second language acquisition (SLA) and also draw on applications of Vygotsky's Sociocultural Theory to (second) language learning (Lantolf, 2011, 2006, 2000; Lantolf \& Thorne, 2007). Within these frameworks, learner factors and contextual factors interact to construct and influence learning and performance. Learner factors include, among others, cultural background, past learning experiences, and language knowledge. Contextual factors include, among others, participants' familiarity with one another, physical location, and materials. Performance is jointly constructed and distributed across all participants. 
Following from these theoretical foundations, the ILOs adopt a learnercentered, project-based approach. The topic and project of an ILO emerge through dialogue with the director of the CLAC program, the graduate fellows, undergraduate students who are participating in the ILO, RCAH faculty and, in some cases, community partners. Any participant can suggest an ILO theme and related product (e.g., poster presentation, video, sculpture). Themes often grow out of issues addressed in the broader college curriculum (e.g., social justice). Intended to provide RCAH students with an immersion experience, ILO meetings between the graduate fellow and the undergraduates are conducted in the world language. The proficiency level of students, of course, determines conversational content during the meetings; it also plays a large part in determining the type of project. ILOs are non-credit bearing and participation is not required. The languages that ILOs are offered in are based on student requests. Students select languages for various reasons such as to get support while taking a traditional language course, to prepare for study abroad, to fill a gap year when they are not taking a language course, or to explore a world language and culture that they have not but want to experience. ILOs also provide our students with the opportunity to pursue a heritage language (i.e., Chinese, Italian, Korean, Spanish, and Vietnamese). The number of ILOs offered each semester in different languages has ranged from four to eleven. At the end of each semester, graduate fellows and undergraduates present their projects at the RCAH's Showcase (http://rcah.msu.edu/academics/language-proficiency/ integrated-language-options). The graduate fellows and RCAH undergraduates provide evaluations of the ILOs at the end of each semester. These take the form of one-on-one interviews, group discussions, and anonymous surveys administered online.

\section{RESEARCH METHOD}

This study originated in observations of patterns of behavior, which included dialogue and interactions among past and current participants in the CLAC program as well as relatively more formal participant commentary (i.e., evaluations) that appeared to contain common thematic threads. A grounded theory methodology (Glaser \& Strauss, 1967) was thus employed not to describe but to codify these data in order to understand and articulate emerging concepts. We supplemented these existing data with a direct and explicit exploration of international graduate fellows' perspectives on the program and their participation in it.

\section{Participants}


Participants in this study included international language fellows who have led ILOs since the beginning of the CLAC program. Seventeen international graduate fellows from 14 countries (China, Colombia, Honduras, India, Iraq, Italy, Japan, Korea, Mexico, Puerto Rico, Senegal, Tanzania, Tunisia and Vietnam) have taken part in the program. After obtaining university IRB approval, we invited all of them to discuss their participation in the CLAC program in a focus group. Ten of the 14, ranging in age from 25 to 39 years old, accepted the invitation. The international graduate fellows varied in their discipline (advertising, communication, education, engineering, linguistics and languages, tourism, urban planning), level (doctoral and master's program), and year in their program (from $2^{\text {nd }}$ year to $6^{\text {th }}$ year). Three participants had recently graduated. The number of years that graduate fellows had been involved in the CLAC program also varied, with one participant who had completed two years of involvement, six who had completed one year, and three in their first year in the program. The authors of this paper were also involved in this process as participantresearchers (Dreyer, 1998, 2016). In line with grounded theory protocol, the researchers' perspectives were not dismissed but were considered additional information and were included in the constant comparative analysis. The second author initially conceptualized and structured the program and is currently the program director. The first author has been involved in the program as an international graduate fellow for two years and at the time of the study was the lead fellow, leading the program while the program director was on leave.

\section{Data Sources}

Two main sources of data informed this study: video recordings of focus groups and program documents (e.g., the director's annual program reports and the first author's reflective notes collected during ILO meetings). The former represents the supplemental data referred to previously and the latter represents the pre-existing data. We conducted two one-hour focus groups with different international graduate fellows in each group. The semistructured questionnaire used for the discussions asked: what graduate fellows had found surprising or unexpected about the CLAC program, how they characterized their experience in the program, what and from whom they had learned, and how they characterized the interplay between the weekly graduate fellow seminars and their individual ILO meetings with $\mathrm{RCAH}$ undergraduates. We asked follow up questions and pressed for examples when necessary.

\section{Data Analysis}


To analyze the focus groups, we followed Powell, Francisco, and Maher's (2003) video analysis model, which included annotating each video and identifying focal instances based on annotations. Each author watched the focus groups videos independently several times, generating descriptive annotations (Glesne, 2006). Repeated viewing sought to refine and complete the annotations. To identify focal instances, we followed a constant comparative method (Boeije, 2002; Glaser \& Strauss, 1967), coding participants' interventions and identifying emerging themes among codes. Finally, the authors shared their annotations, codes and emerging themes. We discussed points of agreement and points of divergence and conducted additional independent viewings to revise initial interpretations. We convened once more to generate agreed-upon themes. We analyzed program documents in the light of the themes that emerged from the analyses of the video data. We discussed and reached consensus about instances in the documents that exemplified or supported particular themes.

\section{DISCUSSION}

During the early stages of our study, we examined the original design (e.g., primary goals, participant roles, ILO methodology) of the RCAH's CLAC program and discovered concepts emerging in the operational model that are key foundational elements of Knowledge-building Communitiesintentionality and agency. We begin our discussion there and include graduate fellow comments corresponding to these underlying concepts that we claim both frameworks share. We then turn our attention to the concept of socialization reciprocity and its realization in the CLAC program, providing examples from participant feedback on the weekly graduate fellow seminars and the ILO meetings.

\section{Knowledge-Building Community: Intentionality and Agency}

Two concepts underlying all KBCs are relevant to the current discussion: Intentionality and agency. KBCs are intentional in that all members come together with the goal of creating knowledge. That is, within a $\mathrm{KBC}$ all members engage in purposeful, relevant interaction, which results in the collective production of knowledge. In turn, this engagement in the knowledge-building process has direct, positive impact on the motivation of KBC members.

The questions the $\mathrm{KBC}$ asks may originate from individuals within the community so that members themselves establish the "agenda for knowledge construction...agency [thus] becomes a key driver of the community learning process" (Hoadley, 2012, p. 291). That is, the focus of a 
$\mathrm{KBC}$ is not dictated from outside the community. Within a $\mathrm{KBC}$ the roles of novice and expert are continuously shifting in the course of complex interactions and negotiations among participants. Furthermore,

[t] he knowledge of the most advanced participant does not circumscribe what is to be learned or investigated.... To the extent that novices [push] the discourse toward definition and clarification, their role is as important as that of those more knowledgeable. (Scardamalia \& Bereiter, 1994, pp. 274-275)

Recall that the original design for the CLAC program required a projectbased methodology for the ILOs and provided general learning goals for both the ILOs and for the graduate fellow seminars. Articulating core elements of program design for a newly created program clearly lends some necessary structure and focus, and provides one with a starting point. Nonetheless, what has emerged in the first three years is a program that has maintained structural integrity while being continuously responsive to all elements of the specific context (e.g., time, place, people) and adapting accordingly. The weekly seminars have become spaces in which international graduate students enter with the intention of considering different ways of knowing, alternative explanations and recombinations of multiple solutions. Each member shares the common goal, in very general terms, of facilitating undergraduate student learning of world languages and cultures. Yet, intrinsic to the CLAC Program (and to KBCs) is the guarantee that goals are fluid, changing based on immediate need, the background and expertise of graduate fellows, and the individual characteristics and abilities of the undergraduate students. Any structural and functional boundaries are flexible, are constantly changing and, to a large extent, are determined by the interactions in which questions, ideas, experiences, and knowledge continuously emerge.

We suggest that the program's conceptualization of the role of international graduate students - the affordance of agency - is a prerequisite for this intentionality to flourish. Collaboratively, all participants are the "drivers" of the program. The substantive, knowledge-building nature of the dialogues of the weekly seminars depend on the respected contribution of each member, who represents a distinct disciplinary, linguistic, and cultural community. "From a social standpoint, the ability to connect discourses within and between communities opens new possibilities for barriercrossing and mutual support" (Scardamalia \& Bereiter, 2002, p. 1373). During these purposeful interactions, we have seen a participant's role continuously shift between that of the expert in, for example, one's 
discipline and linguaculture (Risager, 2013) to that of the novice in terms of, for example, pedagogical experience. We offer one of the more noteworthy examples of the knowledge-building, agentive power of the international graduate fellows.

Recall that the CLAC program was created to complement traditional language courses and to provide opportunities for students to apply and strengthen their knowledge of world languages and cultures outside of the traditional language classroom. Because ILOs are project-based, each undergraduate student has an essential role in the development and completion of the product. However, the ILOs are non-credit bearing and are not mandatory, and, even though each student is responsible for the product, student attendance has been a concern. When students become busy, non-mandatory events are the first to be eliminated. While some absences are the result of scheduling conflicts, illness, or personal obligations, students and fellows report that low attendance stems mainly from the lack of concrete incentives for participation.

This feedback led to devoting numerous seminars, over the course of multiple semesters, to the subject of the college's proficiency requirement. These discussions included topics ranging from the RCAH's commitment to the requirement and the contexts of post-graduation world language use to learner profiles and the availability of human and material resources. To these discussions, graduate fellows brought their experiences as researchers, teachers, and as language learners themselves. Their interactions with RCAH undergraduates in the ILOs also informed the dialogue. These discussions contributed to a proposal for the creation of a Language and Culture Portfolio that would serve as an alternate route to fulfilling the language proficiency requirement. This curricular advancement clearly exemplifies the intentionality that characterizes the graduate fellow seminars and the agency on which it crucially depends. We, of course, are not suggesting that portfolios were invented in the CLAC program seminars. Rather, at a conceptual level, what is accepted as evidence of functional proficiency has been redefined within our particular context.

While we have provided a specific programmatic example of the realization of intentionality and agency, to what extent do these concepts appear in the perspectives of the graduate fellows? "Empowering," "educational," and "supportive" were descriptors that fellows often used in the focus group discussions as well as in their written, end-of-semester evaluations. We offer here a number of representative comments.

"...[we] were co-creating the program and were not simply implementing someone else's vision." 
"One of the great benefits of the [program] was becoming a more reflexive and mindful teacher."

"The program gives us an opportunity to go back and learn more about our cultural identity so that we can teach others about our culture."

"Weekly meetings help us to learn from one another and understand our strengths and areas to grow."

"[I was] given an opportunity to present my ideas."

"Other graduate students are very supportive of each other regardless of background, regardless of accent or [first] language."

These statements clearly indicate the intentionality that characterizes the program, a fellow's sense of agency, and the support for developing agency among the participants. The last statement above is particularly revealing of the other contexts in which international graduate students find themselves; that is, situations in which their language is an obstacle to connecting with members of the academic community. Beyond the individual experiences, this deficit view of the linguistic, cultural, or academic background of international students is often entrenched in programs at the institutional level.

International Student Orientation Models (NAFSA, 2015) outlines recurring topics found in university orientation programs for international students. These programs focus mainly on the transmission of logistical, administrative, and cultural information from the institution to the international students. Subjects include immigration regulations, local support services, 'typical' American classroom behavior, and English language testing. A common characteristic noted in the report is a separate orientation component only for international students so that interaction among all incoming students is either absent or treated as peripheral.

In contrast, we have demonstrated that the linguacultures of all participants create and constitute the interactions which have contributed to the development of the CLAC program. We have provided a specific example of the realization of agency and intentionality in the form of a reconceptualization of the RCAH language proficiency requirement. In the next section, we expand on the concept of socialization reciprocity and its realization in the CLAC program. 


\section{Socialization Reciprocity}

Particular conceptualizations of socialization have implications for international graduate students. A conceptualization that regards students as passive receivers of a community's values, skills and norms limits the role of international graduate students to observe and assimilate the target practices. In practice, however, the role of international graduate students can go beyond the intake of expected values to include the ways in which international graduate students reshape the academy. International graduate students can simultaneously be transformed and transform the values, skills and habits of the community, which we refer to as socialization reciprocity. Socialization reciprocity entails attending to mutually beneficial exchanges in which all participants contribute and benefit. To be realized, it requires a perspective of the agentive power of international students, what they can offer, and the multiple roles they play in academia. More than simply a process, socialization reciprocity also embodies a belief in and commitment to the contributions of every member in a community. Here we focus on reciprocities among graduate fellows, undergraduate students, and the community in the interrelated processes of teaching, participation in weekly seminars, and civic engagement.

Graduate fellows characterized teaching opportunities in the CLAC program in ways that we interpret as socialization reciprocity. Although many international graduate fellows participating in the CLAC program had had research assistantships, few had had teaching opportunities. Language and cultural differences tend to alienate international graduate students, and many programs assume these differences are a challenge in teacher development. In contrast, in the CLAC program, it was precisely these differences that provided international graduate students an opportunity to teach at the undergraduate level. Drawing on their linguacultures, the fellows contributed their skills, insights, and resources to the benefit of the undergraduate students, the other graduate fellows, and the program. At the same time, graduate fellows benefitted from these teaching opportunities. Specifically, participation in the CLAC program informed how graduate fellows think about teaching in different fields and contexts. We consider these mutually beneficial exchanges - that emerged from teaching - as examples of socialization reciprocity.

Graduate fellows' comments illustrate our interpretations of socialization reciprocities that emerged from teaching. For example, one graduate fellows stated that, "I liked preparing and it made me think a lot... it made me think a lot about the way to teach. I think it's going to be useful in my work if I ever go to teaching because I was really trying to think, 
'what is the best way to stimulate them [the students]?' It's different from engineering [graduate fellow's field] but some principles apply." Another graduate fellow noted: "It [the CLAC program] generates this environment where you are free to try different things. It takes away the idea of 'you have to do quizzes, you have to do this.' You're really free to try what you want and I really enjoy that part." More explicitly referring to the reciprocal learning between graduate fellows and undergraduate students, a graduate fellow stated: "When we were having discussions, they [undergraduate students] were giving some of their points of views and they were different from mine... They would [give] some examples of how they think Americans would respond, and they started giving examples of American schools... that are very different in Italy [graduate fellows' country of origin]." In this example, the interaction allowed the graduate fellow to explore issues of multiculturalism with a group of undergraduates. This realization of socialization reciprocity allowed an international graduate fellow to develop insights about undergraduate students, who simultaneously developed insights about the target language and culture. Challenging deficit views that limit international graduate students' teaching opportunities to only observing or shadowing experienced faculty, the CLAC program supported them to teach independently.

In addition to these graduate fellows' characterizations of their teaching, undergraduate students also described these experiences as beneficial. Document analysis reveals that undergraduate students appreciated interactions in the ILO and the graduate fellows' leadership in shaping the projects. In the words of one undergraduate student, "The beginning of the program is so open, so you have the opportunity of learning almost any language you'd like... Then, you have a small group and something good comes out of it. I mean, it could be a service project, you could be singing a song; just something pretty cool that you can say you did in another language". As this quote exemplifies, under the guidance of graduate fellows, students take ownership of the program, shaping the dynamics of their own ILO groups, and expressing the resulting projects and products as their own.

Participation in weekly seminars also reflected socialization reciprocity. Not only did graduate fellows learn from materials shared in those meetings, but they also contributed their own ideas and resources that allowed them to learn from each other. Work in the weekly seminar was beneficial for the program, as reflected in some of the programmatic developments illustrated above (i.e. redevelopment of the college's proficiency requirement). Seminars were beneficial for graduate fellows in 
their work in the CLAC program and also in their own careers. As one international graduate fellow stated referring to weekly seminars: "I learned a lot about the things that were brought up, especially the reflexivity piece, how to get students to reflect about how they learn. That's becoming very important now that everybody is asking what types of things you have in place when you are teaching to make sure you are reflecting on the learning goals... Now in my job applications I am putting quotes from the [article read for the weekly seminar]" Adding to that comment, another graduate fellow remarked, "I agree. They [readings and weekly seminar discussions] were really useful in writing my teaching philosophy. I can include my experience in the ILOs." We interpret these representative quotes as illustrating socialization reciprocity realized through weekly seminars.

The process of civic engagement in the ILOs also reflected the concept of socialization reciprocity. The CLAC program encourages and facilitates civic engagement as part of the college's core values and in response to the keen interest of undergraduate students. In the CLAC program, international graduate fellows drew on their connections with local and international communities. This acknowledgement of the resources that graduate fellows contributed to civic engagement projects helped validate their expertise and fostered a sense of community.

As an example of socialization reciprocity through civic engagement, one CLAC project conducted in Spanish during the fall of 2015 involved seven undergraduate students with differing Spanish proficiencies. The group decided to investigate art in public spaces in Latin American countries. Using an art analysis model that included describing, analyzing, interpreting and judging the piece of art, the group explored a sculpture by Cárdenas, a Colombian artist, in a public park in Medellín, Colombia. ILO meetings included learning the relevant language as well as the cultural components such as the purposes of art and how art may influence public spaces and observers, and vice versa. The group interviewed the Colombian artist to further understand what motivated the creation of the sculpture in that particular park. During the interview students also explored the artist's experience transforming a public park into a safer place through art. During the group's analysis of the interview, students came up with the idea of replicating the artist's initiative at the university - the sculpture and communication with observers - to raise awareness about violence against women. The final product was a video documenting Cárdenas story and the group's intervention (youtu.be/vVcFMM2Soic).

This civic engagement project exemplifies socialization reciprocity. Instead of expecting the international graduate fellow to understand and 
assimilate the cultural practices of undergraduate students, the CLAC program tapped into the graduate fellow's funds of knowledge (Moll, Amanti, Neff, \& Gonzalez, 1992). The international graduate fellow contributed particular knowledge (linguistic and cultural resources, connections to communities in Colombia), while simultaneously learning from community members, and from the individual skills and perspectives of the undergraduate students.

\section{CONCLUSION}

We have examined the development and operationalization of a relatively new Cultures and Languages across the Curriculum program with a primary focus on the roles of international graduate students. Using a grounded theory methodology, we have shown that agency and intentionality are embedded in the program. We have also introduced the concept of socialization reciprocity, which can be defined as mutually beneficial exchanges in which every member of a community is simultaneously transformed and transforms the values, skills, and habits of the community; more than simply a process, socialization reciprocity embodies a belief in and commitment to the contributions of every member in a community.

Through our ongoing examination and interpretation of the data, we have come to the conclusion that the relationships between agency, intentionality, and socialization reciprocity are indeed complex. Each can be signified as a concept, each can be translated into a particular process, each depends on the others, each changes based on specific contextual variables, and each evolves as a result of interactions with the others. The cyclic nature of these relationships makes it difficult, if not impossible, to locate a starting point or to produce a formula for replication. Where does this leave us in terms of the implications of our study for other researchers?

True to a grounded theory methodology, we recommend investigations into the applicability of the concept of socialization reciprocity to other contexts such as programs for preparing future faculty or peer mentoring programs in higher education. We speculate that the concept, of course, will be altered in new contexts with new sets of variables. At the core of the concept, however, is the absence of a perspective that views any member as deficient, which we hope continues to inform and challenge programs in which international graduate students engage. 


\section{ACKNOWLEDGMENTS}

We would like to thank all the international graduate student language fellows who have helped build the CLAC program, including participation in this study. We would also like to thank three anonymous reviewers and Dr. Krishna Bista whose questions and comments compelled us to clarify first for ourselves and then for our readers the concepts we were formulating and the positions we wished to take. We have truly benefited from this communication. Any shortcomings remain our own.

\section{REFERENCES}

Boeije, H. (2002). A purposeful approach to the constant comparative method in the analysis of qualitative interviews. Quality and Quantity, 36(4), 391-409. doi:10.1023/A:1020909529486

DeLind, L., \& Delgado, V. (2009). A faculty guide to civic engagement in the Residential College in the Arts and Humanities. East Lansing, MI: Michigan State University Residential College in the Arts and Humanities.

Dreyer, J. S. (1998). The researcher: Engaged participant or detached observer? Journal of Empirical Theology, 11(2), 5-22.

Dreyer, J. S. (2016). Knowledge, subjectivity, (de)coloniality, and the conundrum of reflexivity. In J. A. Mercer \& B. J. McLemore (Eds.), Conundrums in practical theology (pp. 90-109). Leiden, The Netherlands: Brill Academic Publishers.

Glaser, B. G., \& Strauss, A. L. (1967). The discovery of grounded theory: Strategies for qualitative research. Chicago, IL: Aldine.

Glesne, C. (2006). Becoming qualitative researchers: An introduction (4th ed.). Boston, MA: Pearson.

Hoadley, C. (2012). What is a community of practice and how can we support it? In D. H. Jonassen \& S. M. Land (Eds.), Theoretical foundations of learning environments (pp. 287-300). New York: Routledge.

Lantolf, J. P. (Ed.). (2000). Sociocultural theory and second language learning. Oxford: Oxford University Press.

Lantolf, J. P. (2006). Sociocultural theory and L2: State of the art. Studies in Second Language Acquisition, 28, 67-109. doi:10.1017/S0272263106060037

Lantolf, J. P. (2011). Integrating sociocultural theory and cognitive linguistics in the second language classroom. In E. Hinkel (Ed.), Handbook of research on second language teaching and learning, Vol. II. (pp. 303-318). New York: Routledge.

Lantolf, J. P., \& Thorne, S. L. (2007). Sociocultural theory and second language learning. In B. van Patten \& J. Williams (Eds.), Theories in second language acquisition (pp. 201-224). New Jersey: Lawrence Erlbaum. 
Moll, L. C., Amanti, C., Neff, D., \& Gonzalez, N. (1992). Funds of knowledge for teaching: Using a qualitative approach to connect homes and classrooms. Theory Into Practice, 31(2), 132-141. doi:10.1080/00405849209543534

NAFSA: Association of International Educators. (2015). International student orientation: A common thread. Retrieved from http://www.nafsa.org/ Professional_Resources/Browse_by_Interest/International_Students_and_S cholars/Network_Resources/International_Student_and_Scholar_Services/I nternational_Student_Orientation_Models/

Powell, A. B., Francisco, J. M., \& Maher, C. A. (2003). An analytical model for studying the development of learners' mathematical ideas and reasoning using videotape data. Journal of Mathematical Behavior, 22(4), 405-435. doi:10.1016/j.jmathb.2003.09.002

Risager, K. (2013). Linguaculture. In C. A. Chapelle (Ed.), Encyclopedia of applied linguistics (pp. 3418-3421). London, UK: Blackwell Publishing.

Scardamalia, M., \& Bereiter, C. (1994). Computer support for Knowledge-Building Communities. The Journal of the Learning Sciences, 3(3), 265-283. doi:10.1207/s15327809j1s0303_3

Scardamalia, M., \& Bereiter, C. (2002). Knowledge-building. In J. W. Guthrie (Ed.), Encyclopedia of education (2nd ed., Vol. 4) (pp. 1370-1373). New York: Macmillan.

JOSÉ MANUEL MARTÍNEZ is a PhD candidate in Curriculum Instruction and Teacher Education. His research interests include teacher preparation and mathematics teaching and learning in bilingual contexts.

Email:mart1580@msu.edu

INDIA C. PLOUGH, $\mathrm{PhD}$, is an assistant professor in the Residential College in the Arts and Humanities, and the Director of the Cultures and Languages across the Curriculum program. Her research interests include sociolinguistics and second language acquisition and teaching. Email: ploughi@msu.edu 